\title{
Programa Escola de Hackers como vetor de articulação entre pesquisa e extensão
}

\author{
Thaís Lourençato Trevisan ${ }^{1}$, Adriano Teixeira ${ }^{1}$, Milene Giaretta ${ }^{1}$ \\ ${ }^{1}$ Universidade de Passo Fundo, Passo Fundo, RS - Brasil \\ \{thais.1t0128@gmail.com, teixeira@upf.br, 127979@upf.br\}
}

\begin{abstract}
The School of Hackers Program was created by the City Hall of Passo Fundo, $R S$ in 2014 and offers an opportunity to learn computer programming. With methodological support from the University of Passo Fundo, in this 5 years it has benefited more than 900 people between the ages of 5 and 70 through its 4 actions: Hackers' Nursery, Hackers School, Advanced Hackers School and White Hat Academy. present the deployments of the Front School of Hackers from the social and academic point of view.
\end{abstract}

Resumo. O Programa Escola de Hackers foi criado pela Prefeitura Municipal de Passo Fundo, RS em 2014 e oferece oportunidade de aprendizagem de programação de computadores. Com apoio metodológico da Universidade de Passo Fundo, neste 5 anos beneficiou mais de 900 pessoas com idades de 5 a 70 anos através de suas 4 ações: Berçário de Hackers, Escola de Hackers, Escola de Hackers Avançada e Academia White Hat. Este artigo objetiva apresentar os desdobramentos da frente Escola de Hackers do ponto de vista social e acadêmico.

\section{Introdução}

É inegável que a presença das novas tecnologias esteja cada vez mais em evidência na vida cotidiana dos seres humanos na atualidade. A veloz evolução das Tecnologias de Informação e de Comunicação (TICs) propicia o acesso à informação para população de forma jamais vista e, desta forma, transforma a sociedade em sua estruturação social, de trabalho, econômica, cultural e, especialmente, educacional Quanto mais se avança tecnologicamente, mais os processos são automatizados e maior a demanda por novas habilidades e competências. As competências necessárias para pesquisas acadêmicas, cursar um curso superior ou participar o mercado de trabalho futuro estão diretamente associadas à programação de computadores que, segundo Papert (1985), é um processo natural que promove a qualificação dos mecanismos humanos de aprendizagem.

Para além do proposto por Papert, é possível apontar que ao aprender a programar computadores, os sujeitos são estimulados a pensar de maneira mais criativa, desenvolver o raciocínio lógico, instigar a criar protótipos e a trabalhar em equipe. Desta forma, o uso do computador é defendido como colaborador no processo de construção de conhecimentos, uma poderosa ferramenta educacional, que adapta os princípios do construtivismo cognitivo de Jean Piaget, a fim de melhor aproveitar o uso de tecnologias. Assim, propôs o 
construcionismo, uma abordagem que preserva a ideia de que o sujeito constrói o seu próprio conhecimento por intermédio de alguma ferramenta, como é o caso do computador, por exemplo. Suas ideias se originaram de um conjunto de princípios de pensadores e tinham como objetivo um maior aproveitamento do uso das tecnologias no ensino, ou seja, seus estudos defendiam a construção do conhecimento baseada na realização de uma ação concreta que resulta em um produto palpável, desenvolvido com o computador, partindo dos interesses de quem o produz, assim como Papert se posiciona,

\begin{abstract}
o computador é a ferramenta que propicia à criança as condições de entrar em contato com algumas das mais profundas idéias em ciência, matemática e criação de modelos. [...] O computador deixa de ser o meio de transferir informação, e passa a ser a ferramenta com a qual a criança pode formalizar os seus conhecimentos intuitivos. O programa (a seqüência de ações ao computador) que a criança elabora é o espelho que reflete o seu conhecimento sobre um determinado assunto e o seu estilo de pensamento. Este programa, quando usado como objeto de reflexão, se torna uma poderosa fonte de aprendizagem (1985, p. 9-10).
\end{abstract}

Diante deste contexto, cria-se a necessidade de oportunizar acesso a espaços onde o ensino de programação de computadores seja oferecido a crianças desde a mais tenra idade para que, a partir do desenvolvimento do pensamento computacional, suas competências cognitivas sejam ampliadas. Assim sendo, Resnick (2013) afirma que aprender a programação no século atual é tão importante quanto aprender a leitura e a escrita.

A ideia do pensamento computacional com visão para a educação do século XXI, surgiu com Jeannette Wing, que o define como um conjunto de competências e habilidades básicas que os alunos devem desenvolver a partir do Ensino Básico. Tal autora ainda coloca que, "pensamento computacional é uma forma para seres humanos resolverem problemas; não é tentar fazer com que seres humanos pensem como computadores. Computadores são tediosos e enfadonhos; humanos são espertos e imaginativos" (2006, p. 35).

Não se trata de saber navegar na internet, enviar e-mails ou usar de ferramentas computacionais como o processador de texto ou planilha de cálculo. Pensamento computacional é saber usar o computador como um instrumento de ampliação do poder cognitivo e operacional humano, em outras palavras, é usar computadores e redes para aumentar a produtividade, inventividade e criatividade. Trata-se da ativação de incumbências cognitivas que possam ser realizadas pelo computador e, neste caso, saber programá-lo para cumprir tais encargos. Jeannette Wing ainda apresenta que "pensamento computacional é uma habilidade fundamental para todos, não somente para cientistas da computação" (2006, p. 33).

Papert define que pensamento computacional é um processo de resolução de problemas que inclui determinadas características de disposições. Este processo, por sua vez, é essencial para o desenvolvimento de programas para computador, mas pode também ser utilizado como suporte para a resolução de problemas, independentemente da disciplina, incluindo Matemática, Ciências e as áreas humanas. Dentro desse contexto, Jeannette Wing destaca que, 


\begin{abstract}
fundamentais da ciência da computação. O pensamento computacional inclui uma série de ferramentas mentais que refletem a vastidão do campo da ciência da computação. [...] Ao resolver um problema eficientemente, podemos questionar se uma solução aproximada é boa o suficiente e se falsos positivos ou falsos negativos são permitidos. O pensamento computacional é reformular um problema aparentemente difícil em um problema que sabemos como resolver, talvez por redução, incorporação, transformação ou simulação (2006, p. 33).
\end{abstract}

A ideia de que a programação de computadores ajuda a pensar melhor não é nova. Papert já mencionava a importância dessa atividade para o processo de construção de conhecimento e para o desenvolvimento do pensamento. Em 1971, ele argumentou que a computação pode ter "um impacto profundo por concretizar e elucidar muitos conceitos anteriormente sutis em psicologia, linguística, biologia, e os fundamentos da lógica e da Matemática" (PAPERT, 1971, p. 2). Tais aspectos são possíveis pelo fato de proporcionar a uma criança a capacidade "de articular o trabalho de sua própria mente e, particularmente, a interação entre ela e a realidade no decurso da aprendizagem e do pensamento" (PAPERT, 1971, p. 3).

Neste sentido, com o objetivo de oportunizar oficinas que desenvolvam competências lógicas-matemáticas e de programação de computadores através do software Scratch, surge o Programa Escola de Hackers desenvolvido pela Prefeitura Municipal de Passo Fundo com o apoio da Universidade de Passo Fundo. O Escola de Hackers possui esta denominação devido ao que significa a palavra "hacker": aquele que é criativo e que se dedica a modificar os recursos que lhes estão disponíveis para transformar o mundo à sua volta (TEIXEIRA et al, 2015, p. 113).

O projeto que foi idealizado em 2013 pelo Grupo de Pesquisa em Cultura Digital da Universidade de Passo Fundo, e surgiu de fato em 2014 através da Secretaria de Educação da Prefeitura Municipal de Passo Fundo. Atualmente organiza-se em quatro frentes: O Berçário de Hackers, responsável por atender um grupo de crianças da Educação Infantil fazendo o uso de recursos de Computação Desplugada e do software Scratch Jr.; a Escola de Hackers, que é o foco deste artigo, voltada para o público do Ensino Fundamental II da rede municipal fazendo o uso do software Scratch; a Escola de Hackers avançada que atende alunos destaque do Escola de Hackers com o uso do Scratch for Arduino, Ardublock e C; e a Academia White Hat que atende à Divisão de Atenção ao Idoso da Prefeitura Municipal de Passo Fundo.

Este artigo organiza-se de forma a relatamos a metodologia da Escola de Hackers e seus desdobramentos sociais e acadêmicos ao longo de sua trajetória.

\title{
2. Metodologia da Escola de Hackers
}

A Escola de Hackers foi criado pela Prefeitura Municipal de Passo Fundo em 2014 e vem se desenvolvendo até o ano presente. A cada ano atende e oferece a oportunidade da aprendizagem sobre programação a novos alunos da rede pública municipal, sendo o seu público alvo os pré adolescentes e adolescentes entre 12 e 16 anos que frequentam o Ensino Fundamental II.

Todo ano, novos alunos e novas escolas são selecionadas para o projeto. As escolas escolhidas pela Prefeitura Municipal de Passo Fundo a participar do projeto são responsáveis 
pela seleção de uma turma com em média 15 alunos para participar das oficinas oferecidas pelo programa Escola de Hackers.

Estas oficinas ocorrem semanalmente durante três horas no laboratória de informática das escolas, e são ministradas por bolsistas da Prefeitura Municipal de Passo Fundo que estão cursando suas graduações na Universidade de Passo Fundo. Durante este período de aprendizagem sobre a programação, os bolsistas fazem uso do Caderno Didático da Escola de Hackers ${ }^{1}$ como recurso de material didático, o qual oferece a explicação de diversas atividades a serem realizadas através do software Scratch.

O caderno didático é organizado de modo a criar situações problemas onde, além de refletir sobre as melhores formas de resolução, criam oportunidades de aprendizado e exercício de competências na área de programação de computadores. Os módulos, por sua vez, organizam-se em níveis de complexidade crescente e passam, gradativamente, de atividades individuais de conhecimento do software utilizado, para trabalhos que pressupõem articulação em grupo e a resolução de problemas.

Os módulos, definidos preliminarmente, são constantemente avaliados pela equipe a fim de detectar possíveis alterações necessárias. Para que se possa efetivar um processo ativo de acompanhamento, os encontros semanais desenvolvem-se em torno da avaliação das atividades nas escolas na semana anterior; da identificação de possíveis alterações na dinâmica proposta; e na preparação coletiva do encontro da semana. Esta etapa conta com a presença da equipe executora.

Sendo de acordo comum que aprender programação é necessário para a alfabetização da sociedade atual, o uso do Scratch nas oficinas da Escola de Hackers auxilia a aprendizagem de uma forma motivadora, inteligente, e que desperta o interesse do aluno, sendo possível compartilhar com os demais colegas os projetos realizados nesta plataforma digital. O Scratch é um software que utiliza a linguagem de programação desenvolvido em 2007 no MIT Media Lab e é a principal plataforma de ensino de programação do mundo.

O Scratch utiliza uma dinâmica de programação por blocos, para que as crianças criem programas sem a necessidade de digitar códigos complicados. Esses blocos facilitam o processo de descrição das instruções para a máquina (computador) uma vez que a sintaxe das indicações é definida pelo encaixe dos blocos, contribuindo para minimizar esse tipo de erro, que é muito comum em linguagem de programação baseada na codificação de comandos.

Entre os recursos do Scratch destacam-se as competências para a resolução de problemas e para a concepção de projetos com raciocínio lógico, decomposição de problemas complexos em partes mais simples, identificação e eliminação de erros, desenvolvimento de ideias, desde a concepção até a concretização do projeto, concentração e perseverança, pois é voltado ao usuário infantil e jovem. Neste sentido, Papert coloca que,

é comum os estudantes falharem ao tentar resolver um problema, porque insistem em tentar resolvê-lo por inteiro de uma só vez; em muitos casos, seria muito mais fácil se reconhecessem que partes do problema podem ser resolvidas separadamente e depois unidas para lidar com o todo (2008, p. 90).

\footnotetext{
${ }^{1}$ Disponível em http://bit.do/cdeh.
} 
VIII Congresso Brasileiro de Informática na Educação (CBIE 2019)

Anais do XXV Workshop de Informática na Escola (WIE 2019)

Semanalmente o grupo responsável pela condução metodológica da Escola de Hackers realiza encontros de avaliação e preparação das atividades a serem realizadas nas escola. Nestas oportunidades ocorrem o planejamento das futuras oficinas, o relato das experiências vivenciadas durante o projeto e discussões acerca de trabalhos, pesquisa e a infraestrutura dos laboratórios de informática.

\section{Resultados e Discussão}

Em 2014 iniciou-se a fase piloto do Programa Escola de Hackers, o neste ano foram atendidas 21 escolas municipais, de forma que 312 alunos estiveram inseridos no programa. No ano seguinte, 2015, o programa reduziu o número de Escolas Municipais de Ensino Fundamental atendendo apenas 19, contando com um total de 301 jovens a fim de reestruturar sua metodologia. O projeto foi ampliado para outras faixas etárias dando origem ao Berçário de Hackers, responsável por atender um grupo de crianças da Educação Infantil Municipal, e a Escola de Hackers avançada com os alunos destaque das atividades do ano anterior. Neste ano o Caderno Didático do Escola de Hackers foi criado pelos bolsistas do programa e passou a ser utilizado como base para as oficinas.

Em 2016 o projeto sofreu uma interrupção em função de questões internas da Prefeitura Municipal, oportunidade em que se implementou uma profunda mudança em sua estrutura metodológica, bem como no Caderno Didático.

Quando o programa retornou em 2017 a Academia White Hat também foi incluída no projeto. Desta forma a Escola de Hackers ocorreu em diferentes frentes: Escola de Hackers, Escola de Hackers avançada, Berçário de Hackers e Academia White Hat, atendendo a 147 147 Passofundenses, sendo a maioria alunos de onze escolas municipais.

No ano de 2018 o Caderno Didático foi qualificado a partir de sua reorganização a partir da Taxonomia de Bloom, trabalho realizada durante uma dissertação de mestrado em Ensino de Ciências e Matemática da Universidade de Passo Fundo. Neste ano, os testes executados durante o transcorrer das atividades para detectar modificações nas habilidades lógico-matemáticas e computacionais do alunos apontaram resultados positivos em relação a avanços e aprendizagem de todos os participantes do programa. Formaram-se 79 alunos de cinco escolas municipais.

Com os bons resultados da nova metodologia de oficinas implementados no ano de 2018, em 2019 o projeto foi expandido para um número maior de escolas, atendendo nove ao total. Desta forma, estão participando do programa 160 alunos da rede municipal, com o acompanhamento de dois monitores por escola.

No gráfico abaixo (Figura 1) apresenta-se a relação de alunos ao longo dos anos do projeto, sendo perceptível que os número de estudantes diminuir significativamente após 2015 por conta, principalmente da necessidade de aprimoramento metodológico e reorganização do caderno didático. É preciso pontuar que, a fim de testar as modificações feitas, a diminuição do número de escolas foi uma opção intencional e que, uma vez testado a eficácia da metodologia e do caderno didático, iniciou-se a ampliação do número de escolas e estudantes atendidos. Assim, com as mudanças metodológicas a partir de 2017, da reformulação do Caderno Didático do Escola de Hackers e dos resultados positivos de 2018, em 2019, o projeto conseguiu ser ampliado novamente tendo como principal objetivo fomentar a criação de uma política pública que atenda a todas as escolas do Município. 
VIII Congresso Brasileiro de Informática na Educação (CBIE 2019)

Anais do XXV Workshop de Informática na Escola (WIE 2019)

Figura 1: Número de alunos atendidos pela Escola de Hackers de 2014 a 2019.

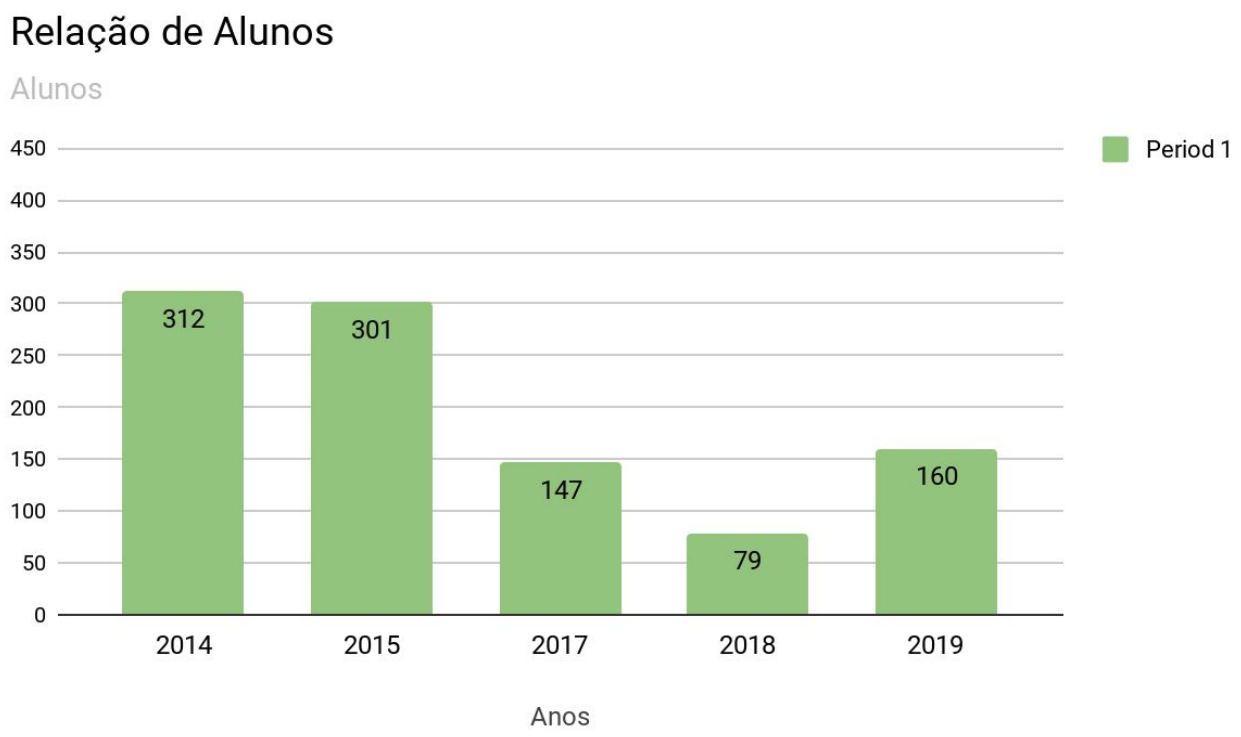

Fonte: Arquivo do Programa Escola de Hackers.

Ao longo do projeto, não só alunos da rede pública municipal tiveram a oportunidade de aprender com as atividades propostas, mas também os alunos da Universidade de Passo Fundo como monitores da Escola de Hackers. A cada ano novos monitores, advindos de cursos de graduação relacionadas à tecnologia e à formação de professores, tem a oportunidade de ministrar as oficinas da Escola de Hackers. Durante estes cinco anos de projeto, um total de 25 bolsistas estiveram envolvidos das atividades do Escola de Hackers, dando origem a diversos trabalhos acadêmicos, dos quais destacamos: publicações, participação em eventos, capítulos de livros e a elaboração de dissertações e teses.

Em congressos de tecnologia, educação e ensino foram apresentados 26 trabalhos relacionados ao programa publicados em anais de eventos, sendo 16 internacionais. Também vinculado ao projeto há 15 publicações em periódicos em forma de artigos, relacionando ao Protagonismo Juvenil na Escola de Hackers, à formação de professores, aos seus desdobramentos sobre os processos que auxiliam na aprendizagem e sobre a metacognição. Em relação a livros, existem 8 capítulos publicados e 3 livros publicados pelos participantes do programa.

Sobre trabalhos de conclusão de curso, o Programa Escola de Hackers foi tema de duas produções, uma delas vinculada ao uso de aplicativos gamificados para identificar as potencialidades dos alunos e o outra acerca do estímulo do aplicativo gamificado para as atividades físicas. Sobre as dissertações de mestrado existem 5 trabalhos que abordam assuntos relacionados à programação de computadores para educação infantil. Destas, 4 são na área de Educação e uma em Ensino de Ciências e Matemática. As temática são:, o protagonismo juvenil na Escola de Hackers, o desenvolvimento do raciocínio lógico-matemático e o impacto do programa Escola de Hackers no ensino fundamental II. Destas dissertações, uma delas resultou no livro do Caderno Didático atual utilizado no programa como produto educacional e no livro chamado Projeto Escola de Hackers como Potencializador do Protagonismo Juvenil (2018). Por fim, três teses de doutorado em 
VIII Congresso Brasileiro de Informática na Educação (CBIE 2019)

Anais do XXV Workshop de Informática na Escola (WIE 2019)

Educação abordam assuntos relacionados a programação de computadores e metacognição, o uso da tecnologia para auxiliar na retomada de atividades físicas e a formação computacional para professores. Neste sentido, foram 78 trabalhos acadêmicos originados na Escola de Hackers nestes 5 anos de existência do projeto.

Figura 2: Produção acadêmica originada na Escola de Hackers.

\section{Produção Acadêmica}

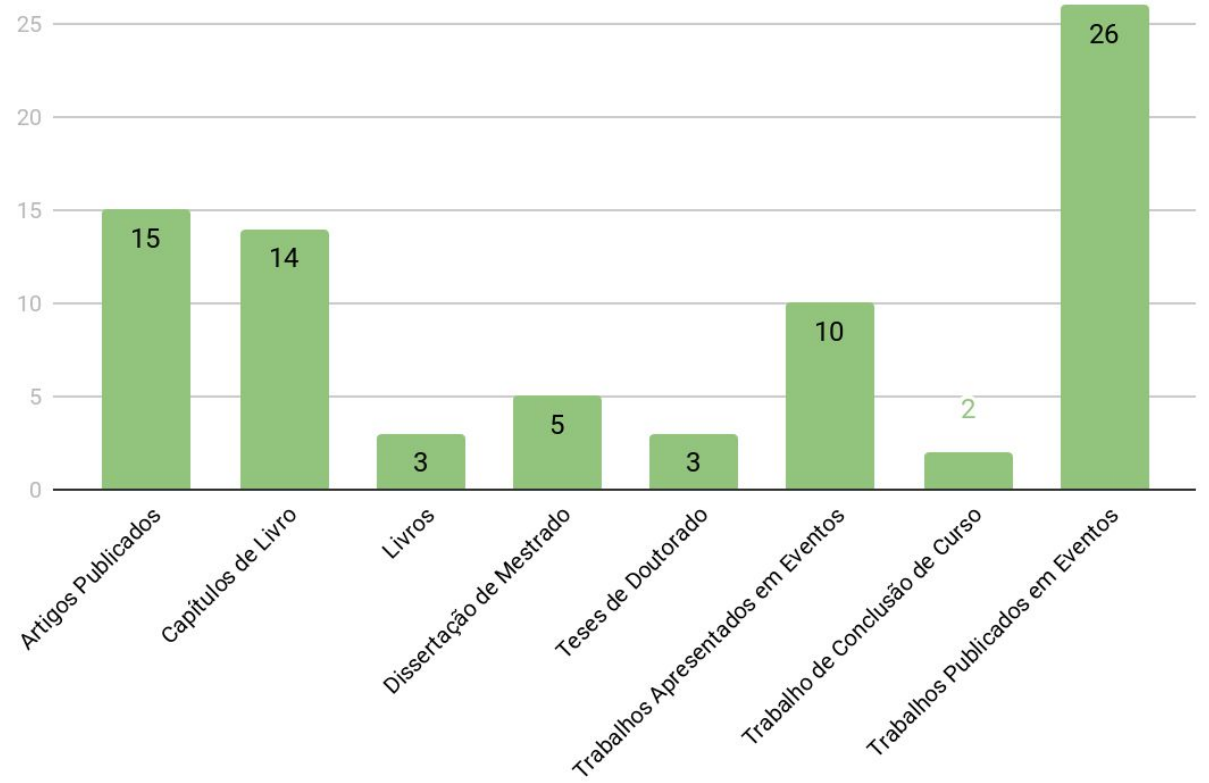

Fonte: Arquivo do Programa Escola de Hackers.

Com o programa obtendo cada vez mais resultados positivos em relação ao ensino da programação e o desenvolvimento do raciocínio lógico matemático nas escolas da rede municipal, além das apresentações e publicações científicas, o Programa Escola de Hackers ganhou o Prêmio Líderes \& Vencedores para a Prefeitura Municipal de Passo Fundo na categoria Referência Educacional no ano de 2015, obtendo notoriedade também na mídia dos jornais e sites de Passo Fundo. Desde 2014, quando o projeto surgiu, os monitores, alunos e coordenadores do programa vem sendo entrevistados e relatando suas experiências com o uso da programação em sala de aula.

Nos jornais da cidade de Passo Fundo e em uma revista, o Programa Escola de Hackers já foi pauta de mais de 45 notícias relacionadas ao início do projeto, alunos formados, escolas participantes e recursos utilizados. Também é possível encontrar mais de 
VIII Congresso Brasileiro de Informática na Educação (CBIE 2019)

Anais do XXV Workshop de Informática na Escola (WIE 2019)

20 notícias sobre o programa no site da Universidade de Passo Fundo, da Faculdade Meridional e dez no site da Prefeitura Municipal de Passo Fundo.

\section{Conclusões}

O Programa Escola de Hackers da Prefeitura Municipal de Passo Fundo, com o apoio da Universidade de Passo Fundo, vem causando impactos positivos na comunidade de modo que oportuniza a aprendizagem de programação de computadores em diversas faixas etárias. Além o desenvolvimento das habilidades relacionadas à tecnologia, o programa também tem como foco o desenvolvimento do raciocínio lógico-matemático, da criatividade, da autonomia e de um melhor desempenho nas disciplinas que necessitam de maior foco para a aprendizagem significativa. Com as melhorias das metodologias das oficinas desenvolvidas todos os anos, o rendimento dos estudantes é cada vez mais significativo, podendo concluir que o Programa Escola de Hackers mobiliza positivamente e ensina efetivamente seus participantes.

Sobre os impactos sociais causados pelo Programa Escola de Hackers é possível citar inúmeros benefícios às escolas e comunidades onde o projeto foi inserido ao longo destes 5 anos. Devido a necessidade de atender a demanda dos novos hackers com recursos tecnológicos suficientes para a realização das oficinas, os laboratórios de informáticas das escolas anexas ao programa passaram por diversas manutenções ao longo do tempo para melhor atender as necessidades de cada turma de alunos, tornando os laboratórios das escolas mais eficientes e funcionais para toda a comunidade escolar.

Também é importante ressaltar que, apesar da tecnologia computacional ser parte do cotidiano do jovem atual, muitas das Escolas Municipais de Ensino Fundamental atendidas pelo programa estão localizadas na periferia de Passo Fundo, fazendo com que muitas vezes o primeiro contato com a programação, o acesso a internet e a tecnologia se de por meio de projetos como a Escola de Hackers. A oportunidade de estar vinculado a tecnologia e a programação desperta habilidades ainda desconhecidas pelos jovens, podendo vir a ser de grande influência em suas escolhas futuras relacionadas aos estudos e ao mercado de trabalho.

Através do empenho e dedicação ao longo das oficinas, os alunos que obtém destaque em suas habilidades de programação e criatividade são selecionados para dar continuidade a sua busca por conhecimento nesta área. A Escola de Hackers Avançada trabalha com estes alunos, os quais ganham bolsas de estudo em um ambiente inovador e criativo, onde lhes são ofertados mais possibilidades tecnológicas a serem desvendadas neste processo de alfabetização computacional.

Para além de seus desdobramentos sociais, apontamos que as ações do projeto tem sido foco de produções acadêmicas que buscam contribuir para o avanço da temática relacionada aos desdobramentos da programação de computadores na educação e no desenvolvimento cognitivo infantil.

\section{Referências}

PAPERT, Seymour. Teaching children thinking. Massachusetts Institute of Technology Cambridge, MA, USA, 1971. Disponível em: <https://goo.gl/9is34j>. Acesso em: 28 jun. 2019. 
VIII Congresso Brasileiro de Informática na Educação (CBIE 2019)

Anais do XXV Workshop de Informática na Escola (WIE 2019)

. Logo: computadores e educação. São Paulo: Brasiliense, 1985.

A máquina das crianças: repensando a escola na era da informática. Porto Alegre: Artmed, 2008.

RESNICK, M. Learn to Code, Code to Learn. EdSurge, 2013.

TEIXEIRA, Adriano et al. Programação de computadores para alunos do ensino fundamental: A Escola de Hackers. Anais do XXI Workshop de Informática na Escola (wie 2015), [s.1.], p.112-121, 26 out. 2015. Sociedade Brasileira de Computação - SBC. http://dx.doi.org/10.5753/cbie.wie.2015.112.

WING, Jeannette M. Computational thinking: it represents a universally applicable attitude and skill set everyone, not just computer scientists, would be eager to learn and use. Communications of The ACM, v. 49, n. 3, p. 33-35, mar. 2006. 